Science, paraprofessionals, and general faculty and students. Special invited guests were the assistant/associate directors of public services and heads of reference departments at the University of Texas System libraries.

The keynote address was given by Pat Molholt, associate director of Institute Libraries, Rensselaer Polytechnic Institute. Her remarks were followed by responses from Cynthia Kehoe, librar- ian, Balcones Library Service Center, and Dennis Trombatore, librarian, Geology Library, both at the University of Texas at Austin. Their presentations were followed by a discussion between members of the audience and the panel. The three addresses and a summary of audience comments by John Tongate, 1989/90 chair of the Reference and Information Services Committee, are presented here.

\title{
The future of reference III: A paradigm shift for information services
}

\author{
By Pat Molholt
}

\author{
Associate Director of Institute Libraries \\ Rensselaer Polytechnic Institute
}

\section{Business-but not as usual}

This will be a talk about walls, not necessarily walls that divide, but ones that provide structure, definition, and containment. I will talk about learning to detect them by means other than bashing into them, and I'll talk about relocating, repairing, and removing them. I'm going to begin by throwing up a new wall that blocks your usual paths.

\section{Tomorrow is a new day}

I have been authorized to make an announcement: When those of you who are reference librarians on this campus leave this meeting today, I want you to take a good look around this library because it's the last time you'll see it as an insider. Starting tomorrow you are being relocated to the Graduate School of Business building. The terms of your employment are changed-you are being given three months of salary and the opportunity to become an Information Entrepreneur. There will no longer be a reference department inside the library. For the next three months you will be allowed into the library free. After that an hourly rate will be charged. The clock will start when you enter the building and stop when you exit. The rate will be $\$ 100$ per hour with rate adjustments made every six months.

You will be charged for loans at $\$ 25$ per item per day, photocopies will be $\$ 10$ per page plus royalties, and access to the online catalog will be $\$ 100$ per hour.
Undergraduate students will be given electronic pass cards credited with the equivalent of one free hour per day of classes (if a semester is 120 days long, the student will have 120 hours of free library use). It is likely this will more than meet their needs, since reserve room activities will be entirely restructured; much of the material will be scanned into online files, the remainder will be relocated outside the library. Undergraduates will be charged for loans and photocopies at the above mentioned rates.

Graduate students, faculty, researchers, staff, and administration will have to obtain information services from the Information Entrepreneurs or pay the same rates as you do. Their inadequate information-seeking skills will come to the fore immediately, creating a quick business opportunity for the displaced reference staff-the Information Entrepreneurs. By the way, the libraries will be open from 9:00 a.m. to 5:00 p.m., Monday through Friday.

How did this happen? I, an alumna of 1970 , bought the library. In the budget crunch I proposed to take the library off the university's hands and run it like a business-it seemed like a better deal than donating a million dollars. The university, I must say, jumped at the chance to get rid of this sink hole of resources. After all, selling the library really only follows patterns already establishedgrounds keepers, food services, cleaning services, printing services, media services, repairs, and construction services are no longer part of the university's overhead on many campuses. Their fees are 
charged back to the units and individuals who use them. You may notice that a lot of them have the word "service" in their name too. And don't forget the Federal government with its contracting out for library services. And industry-only a few weeks ago Rensselaer's library was approached by IBM with a suggestion that Rensselaer take over four or five of its libraries that are in the upstate area-they already have such an arrangement in Kentucky.

Crazy! Can't happen! Simply stupid! Actually, I wonder how Steven Jobs or Donald Trump would handle it? At least suspend your skepticism long enough to wander with me along this perhaps unusual wall and consider what the effect of it is. Why did I set the scene as I did and put substantial prices on library access? One impetus was the concept that "free" equates to having no value, or the designer label syndrome-if you're not wearing Reeboks at $\$ 75$ a pair you may as well not leave the house. Things that cost a lot have more credibility, often for good reason. Yet there is so much confusion in our profession about how to assign value to what we do that we simply don't assign any. (Even in my own case, where we charge other campus units for programming of files, and for the input and editing of data for those files, we don't charge for the most valuable part-the design of the file itself.) Librarians are fighting price increases and trying to maintain the status quo. Our problems ought to be ample evidence that we are not in a sustainable situation. But money issues, while they contribute, also confuse my real purpose. Reference is the key. The functions of interpretation, instruction, query formulation, and needs assessment serve to unlock doors in the wall. Let's look at some of the details of this crazy new library.

The provision of three months of salary continuation was meant to have you quickly focus on the problem, without immediately threatening your survival. Your competitors will be charged from day one; you have some time to band together, assess your capabilities-both strengths and weaknesses-and form your own walls around specialties and preferences. Free access gives you a running start, gives you time to establish new work habits and patterns, and allows you to give your customers a price break as an enticement or incentive during your learning phase. Why do you need a learning period? I would be surprised to find a reference librarian today who asks herself or himself, "What effect does what I am about to do (have a cup of coffee, spend half an hour paging through Psych Abstracts, spend five minutes on a phone call to Memphis to a colleague who knows the information I need) have on what I will earn today?" To me, systematically asking such a question is an exhausting thought, but also an exciting one.

Today when you "walk into" a BRS or Dialog database you easily pay $\$ 100$ an hour. We always complain about the feeling that the meter is running-because it is. Real dollars are being spent and the logoff at the end tells you exactly how many real dollars. The effect is that you perform differently when the meter is running-the same should be true when the meter is running on your time in the library building, or when you're accessing its online services. Such an attitude will make you a more demanding customer. The inefficiencies you now tolerate will cost you, just as your inefficiencies will cost others.

Loans at $\$ 25$ a day. This is a coming-to-life of that old adage that librarians are only happy when all the books are safely on the shelves. In this scenario I have to justify, in economic terms, not having a book on hand since it is the material on the shelf that attracts other customers-that's the only way I can make money. If one person takes it out, it better be worth it to me to deny access to the others who may need it. Today Professor Smith may have dozens of books out for months and months-is she really using them most of the time? Of course not-she would, however, at $\$ 25$ a day, or even $\$ 5$ a day. There's an interesting problem here. One of the properties of information is that it can be shared simultaneously with many users. The packaging of that information, however, may prevent that from happening. A solid, singular object such as a book confines the information contained in it so that sharing follows economic principles like those applied to car rentals, rather than those appropriate to information usage.

As for the $\$ 10$ a page photocopying-I'll get you one way or another. If you sit down to copy it, it's at $\$ 100$ an hour; if you check it out for reading overnight, or photocopy it elsewhere cheaper, it's $\$ 25$. As long as this is a monopoly, and other libraries adhere to their traditional rules, pricing is pretty easy to determine. The rules I am referring to are those such as: libraries lend to libraries, not to individuals (Information Entrepreneurs would purchase the right to borrow in the library's name); patrons who fall outside one's primary clientele are severely restricted in their borrowing privileges (so going to the library of another college in the area will not help much), etc. Besides, we have all argued that a library system as big and well developed as the University of Texas at Austin is a unique resource that simply can't be found anywhere else in the region. If that's true it only makes my business case stronger.

I've tried to protect some access for the undergraduates all the while fearing they have a basic skills problem. For them, more than anyone currently in the educational system, the need to become efficient and effective information workers is critical to their success. Daniel Bell's "post-industrial society" is finally, and seriously, taking root. It's not only what you know (the traditional role of 
university training) but how you continue, throughout your life, to find out more-that is critical to our students' future.

Graduate students, on the other hand, have to factor into the cost of their education the cost of information - as they already do for books, calculators, and microcomputers. A faculty member at Rensselaer recently calculated that the cost of a slide rule, in its day, was in the same proportion to the cost of education as the microcomputer is today. Information access and information "tool kits" (software, expert systems, etc.) are just the next step in transferring costs to the buyer. It's unfortunate that information technologies don't have the same "shelf life" as the slide rule did.

As for faculty, we can already observe telltale patterns. Faculty in the sciences and engineering live a different information lifestyle than those in the humanities and social sciences. Physicists, biologists, and civil and environmental engineers use grant money to pay for remote database searching; they send graduate students over to find and retrieve relevant information. They, as a group, are the information rich. At the other end of the spectrum is the diligent English professor, the budding history scholar in the library poring over books and journals. Actually, the distinction of information rich and poor is not the correct one. There is a plethora of information for all. The dividing line comes in how it is accessed and by whom.

Let's go back, just briefly, to what happens tomorrow morning when the reference librarians find themselves on the outside. Besides going to the local small business organization for development and start-up funds to buy those things you now take for granted (including the telephone), you will face two major challenges. One will be to learn, and I mean really learn, who your potential clients are. The other is to advertise-both what information services you can provide and how good you are. That last one may make you squirm - after all, we are trained to do our jobs quietly, to be self-effacing. The real world doesn't work that way. Businesses bombard you through all available media with information on what they do, and how well they do it, brand names included. Even the legal profession is in the act-what they lack in taste, they make up for in enthusiasm- -Been hit by a car? Call me!"

Another of my purposes with this scenario was to point out how little we know about the true needs of our patrons, including their preferences and work habits. On your own you would have to go from office door to office door making personal contact, learning in reasonable detail what patrons/ clients do. What can make a difference to them in their work that provides you with an opening for your service? Many of them may not even recognize an information problem, even when it stops their research cold. No more sitting behind a desk waiting for someone to come to you. Ah, but you say, you're busy now, working inside the library. But, I ask, busy doing what? Telling the freshmen where the bathroom is, and repeatedly, in serial fashion, helping seniors research a paper-their first paper? Surely there is more to life as a reference librarian than this! It is my perception that very few reference questions involve anything remotely resembling the kind of in-depth reference assistance we were trained to do.

With the likely exception of branch librarians, we simply don't know our clients well enough, nor are any of us working smart enough at handling repetitive functions in more efficient ways. Every time we teach another graduate student how to use Social Science Citation Index to track the spread of research ideas, unless the individual is willing to pay for that private tutoring, we're wasting time. For that sort of thing we need to use simple expert systems, even HyperCard ${ }^{\mathrm{TM}}$ applications, freeing us up for more interesting and cost-effective duties.

One of the issues you will have to deal with as an information entrepreneur is that of overhead - the switch from being part of it to charging to cover it. As you organize yourselves to share expensive resources and benefit from economies of scale, you may suddenly decide you need clerical support. Think about what kind of support you have nowI mean support you truly have control over to answer your phone, type your letters, etc. I would hazard a guess that such support is thin, if existent at all. As an entrepreneur you may need a one-time consultant to help you set up a do-it-yourself billing package, rather than a permanent helper to answer the phone and put the letters you have already completed on your word processor into their envelopes.

While you're scurrying around outside, what's happening inside the library? The circulation staff is down to two; janitorial staff is cut way back, for obvious reasons; the administration has been cut in half, and most of the remaining are accountants (which you always suspected was their focus anyway); technical services is dramatically changed. Not only are there fewer individuals, most of them have chosen to move up to the more open and spacious quarters once occupied by the reference unit. More seriously, however, their work has changed. A quarter of them do acquisition work, a quarter of them do cataloging-nearly all of it is copy cataloging; no one does any classification. Although the LC class numbers are listed in the online catalog to facilitate finding materials on related topics, the Cutter line is omitted and all new items are shelved by accession number. The remaining half of the staff do in-depth subject indexing, further justifying the $\$ 100$ per hour of catalog connect time. You see, I, as the owner of this vast 
pile of books, have to enhance the availability and accessibility of what is in the collection in order to be competitive with other resources. And you, who are now relying on the library for a living, will demand more from it in the way its services are represented and the value you get for your money.

While I'm on the topic of the collection, why do some books never circulate? Some of it is due to poor selection, certainly, but some of it is due to lack of discovery-the lack of an adequate service orientation which would make the content of the books, and other non-electronic resources, accessible. Just providing open access to a million books doesn't do it. Also, and needless to say, there will be tremendous pressure on my part not only to acquire materials quickly, but to get them into the system and on the shelves. A book on a backlog shelf can't earn its keep and is a liability.

Have I made any money yet? I've cut personnel costs dramatically; I've increased acquisitions and have an order out for more shelving to put up in some of the large study areas; the budget breaks down to $30 \%$ salaries, $50 \%$ acquisitions, and $20 \%$ investment-mostly sunk into research for new methods and techniques for access and dissemination-my key to success in the future.

Clearly there are problems with this scenario. Information becomes scarce, and valuable. Faculty begin to barter information, trying to work around the large storehouse of information by finding alternate sources. This causes great inefficiencies and eventually the old adage, "Time is money," will surface. Users turning to other libraries will find, however, that traditional libraries will not serve them without their physically going to them (if one can even obtain permission to get in). Users will find willing help in commercial services, including, of course, their accompanying fees.

There is one other interesting aspect that is not insignificant. There will be those individuals who will bemoan the lack of "social space for inquiry and analysis," as the ASIS 2000 Report $^{1}$ described one role of the library. I'd only like to point out the enormous cost of that social space in its current form and suggest it is more important to the undergraduate looking for a date than the faculty member trying to solve a problem in condensed matter physics.

Do I like this "new library?" No, I don't. It was only an imperfect exercise in imagination intended to unsettle you, to till up some solid, hard-packed

${ }^{1}$ Ann E. Prentice, "Reports from the Think Groups Created in Support of the ASIS 2000 Project," Bulletin of the American Society of Information Science 16 (October-November 1989): 11-29. earth so I could plant a few seeds or set down a foundation for a new kind of wall.

\section{Paradigm shifts are painful}

What I'm actually talking about is a paradigm shift-a situation where an organism or an organization which has been functioning at a kind of equilibrium, building up inertia, changes in a quantum way. Certainly the changes I was suggesting with the Information Entrepreneur represent a paradigm shift. Another example is the change being suggested by Sharon Rogers, and others, regarding the role of the scholarly journal in the academic village. Her "Point of View" article in the Chronicle of Higher Education ${ }^{2}$ a few months ago represents a paradigm shift. The article suggests alternative, electronic-based mechanisms for the delivery of scholarly information, and recommends enhancements to the editorial process, including methods of capturing readers' comments, and control by a board of governors which includes universities. This represents an entirely different environment for scholarly "publishing" and its role in the tenure and promotion process. As you might imagine, paradigm shifts are painful. They result in nearly total change requiring growth on the part of every individual involved. To move through them successfully requires imaginative leadership, experimentation, and flexibility.

In the case of a research library model proposed by a group of my colleagues and me, the paradigm shift reached across traditional boundaries. An article in the Journal of Academic Librarianship ${ }^{3}$ last year set out the basics of this model for the research library of the future. The basic tenets of the model were a restructuring of the library into three components. The first has responsibility for the existing and future print-on-paper and microform collections. It is staffed by high-level support staff, or paraprofessionals, trained in servicing those collections, including preservation techniques. I want to skip over for a moment the second, or middle component, and go to the third component. This piece is staffed by librarians with strong subject backgrounds and trained in effective interpersonal communication skills. They will reside, or spend the majority of their time, outside the library assisting clients in framing information problems, interpreting information resources, and

${ }^{2}$ Sharon J. Rogers and Charlene S. Hurt, "How Scholarly Communication Should Work in the 21st Century," Chronicle of Higher Education 36 (October 18, 1989): A56.

${ }^{3}$ Anne Woodsworth et al., "The Model Research Library: Planning for the Future," Journal of Academic Librarianship 15 (July 1989): 132-138. 
gathering from the field an understanding of what is needed, both in resources and in improved access techniques to existing resources. I skipped over the middle component because one needs to understand the two framing components to understand that the middle piece interfaces with both sides, not directly with the users. The middle component is a systems design function that is responsible for providing enhanced access to the paper-based collections, on one hand, and to the electronic resources on the other. It is staffed by systems designers, artificial intelligence experts, indexers, linguists, and the like. In addition, I would personally argue that the responsibility of this tripartite group for information in the new academic environment in not just a responsibility for traditional "library" information, but for information and information systems campuswide.

There are several dangers to non-conformity, to pushing paradigm shifts, especially when they involve new roles and responsibilities. Initially there is a non-acceptance by those in authority. You hear statements like: "That's not your job," or, "Your training doesn't fit." Going along with this is a need for the university's administration to readjust its image of the librarian and its expectation of skills. Librarians have a strong stereotype to overcomesome of which we perpetuate ourselves-so be prepared to be persistent.

If we are promoting change that is more than cosmetic there will be a need for realignment of work distribution; in particular, responsibility for new activities must be sorted out between units. You can't just start one Monday morning by announcing this is Change Day. Tremendous preparation is involved-input from all concerned, validation of the proposed change, determining new protocols, and, finally, the transfer of duties or the addition of new activities.

The most important aspect of the change process is having a vision-preferably one that has been jointly arrived at and is widely shared. Normally an organization starts with developing a plan, and once the plan is done someone is assigned to implement it and everyone walks away feeling, "Well, that job's done." That's one big reason plans fail. The last thing you need in a dynamic environment is a static plan. If people try to follow it, it causes nothing but constant frustration; it's much easier to put it on the shelf and ignore it, only to take it out annually to check where things have gone of their own accord, compared to where you thought they might go.

A vision is different from a plan-it's something that hangs around in your head, a kind of compass needle to help in navigation. That is not to say there are not specific plans and goals, but they are bonded together by a grand idea. When attempting to focus on a vision, whether for a department or an entire organization, you need to take a functional point of view-in fact, the users' point of view. You need to question everything, be suspicious of statements like, "Well, of course we have to do A, B, or C." Ask what the value of A, B, or C is to the mission of your institution, or what purpose it serves for the user. Listen for the small voices, those that you may not often hear and, above all, consider everything.

We recently went through such an exercise at Rensselaer. Six department heads and two administrators met outside the library for three sessions of nearly four hours each. Nothing was sacred; everything was thrown on the table for discussion. The approach was a kind of zero-based plan. Yes, it was threatening to some but we tried hard to have everyone come out understanding that we were a stronger and more viable organization after the process. We all understood what functions we were going to continue, and why; what we had jettisoned, and why; and what new functions we were taking on and how they fit into the vision. There are timetables and milestones; people have been moved, tasks reassigned, and in some cases there are totally new job descriptions for existing staff-voluntarily agreed to by negotiation. We have a vision, but we also have a real set of actions and consequences. In six months we'll do it all over again-reassess, readjust, reconfirm. The process is more important than the plan.

\section{Tomorrow's library- a concept not a place}

In the most simplistic terms there are two aspects to a library. One is its collection of information, in all the object-based forms we know. The other aspect is the intellectual "tool set," the skills embodied in the staff that sets librarians apart. As access to electronic information resources increases, the intellectual capabilities of the staffthe skills of collocating, organizing, and making information accessible and the complementary skills of identifying, locating, and getting inside the contents of the information packages-grow in prominence. As I have said frequently, there will be less on the shelves and more on the wires.

This is not to deny the unresolved problems caused by the rise of electronic-based information. Computers heighten inequality; they require specialized knowledge unique to particular hardware and software. Books, and other print-based resources, facilitate equality; one has only to pass the barrier of literacy and information is readily available. We are also hampered by the confusion between computers as access vehicles and as delivery vehicles. No one who looks seriously at the use of information technologies is willing to suggest you will be sitting in a dimly lit room reading for hours from a flickering video monitor. The technologies 
open up alternative ways to access information and new ways to deliver it-local printing options, and file transfers and merges that bring subsets of text under control for later access. The problem many libraries are experiencing with "excessive" printing of CD-ROM information is a good example. No one wants to read a lot of information on a screen; even downloading it to a floppy disk, as is sometimes suggested, is only an intermediary step to finding a way to put it on paper. One can't rethink one piece of the puzzle and assume no changes in the surrounding pieces. We need to adopt a systemic approach. For example, as computers and other technologies become truly effective in delivering instruction, a series of changes will course through the academic environment. Not only will teaching methods and course content change, but scheduling, methods of examination, hours of instruction, and availability of faculty will all change as well. Change at the level of a paradigm shift is not a matter of adding a new layer of bricks to the wall, but making new openings, reversing the flow around it, or tearing it down altogether.

In the same context, automating reference isn't just adding a few terminals at the delivery site so librarians can do what they normally do but in a faster way. Change in this area may mean having evening reference librarians work at home, communicating with patrons via e-mail and phone, being able to electronically "look over the shoulder" of a patron who is having a problem with an online search in the catalog, or directing another into an expert system that will instruct them on the use of a reference tool.

Looking at a library as a concept rather than a place begins to open up our thinking. In the very near term it is important that we draw our attention away from the collections, the objects, and look at the services, because, in my view, we can already, quite clearly, see change occurring. What are some of the skills that can be turned into more service?

Librarians need to provide deeper, fuller, and more accurate intellectual access to all information. The design and implementation of new indexing methods is critical in the machine-based environment. Even for that information still captive between book covers, access is key. For some interesting forefront work, read what Suzanne Humphrey and her colleagues are doing at the National Library of Medicine. ${ }^{4}$ Her work is not just enhancement, but represents an exciting rethinking of long-term problems from the perspective of both the user and the indexer. Humphrey has created an expert system called MedIndEx that

${ }^{4}$ Suzanne M. Humphrey, “A Knowledge-Based Expert System for Computer-Assisted Indexing," IEEE Expert 4 (Fall 1989): 25-38. builds indexing around conceptual frames that relate concepts and entities to each other. The result is indexing that taps into a rich, already existing body of knowledge based on the MESH subject vocabulary. This, in turn, allows both for more accurate and consistent indexing and more precise and complete recall.

Another service brought out in the opening scenario is the need for a stronger, more proactive role in bibliographic instruction. We need more than ever to reexamine our time-consuming one-on-one activities. The demographics of the college-age population are changing dramatically, and our universities are taking in a broadening spectrum of students. The backgrounds and skill levels of our entering students are more varied and, while that provides a richer mix of students, it also necessitates a look at how we have provided certain services in the past. Bibliographic instruction is an investment, both for the student and for the librarian. The more sophisticated the user, the better that person is served in the long term and the more interesting our work becomes. I don't see why we can't package some basic information in creative ways on a floppy disk and hand it out at student orientation, for example. When a student or a faculty member decides at 10 in the evening that they need to use the online catalog, why not let them pop in their disk and get a tour? Yes, we have help facilities online, but you need some sophistication with the catalog to even get to the help part. These are not new ideas. Several libraries are using HEA Title II-D money to begin such projects. For the rest of us, every time we agree to a private tutorial session, we reinforce expectations for such service. Let's rethink this and learn to "Just Say No" while providing some more cost-effective and staffeffective methods of delivery.

A third service area is one that the profession has gone around on for a long time, and we need to fish or cut bait, as the expression is. I am referring to the neutrality of librarians in providing information. In time we will be putting less on the shelves, and the whole art of collection development will take on a secondary role. What will be needed in its place is a more intense effort of assisting users in finding the information they want, evaluating it based on their criteria, and repackaging it, perhaps in summary form, or analyzed and ready to be incorporated into their work. The Information Entrepreneur exists today as the information broker. If we look beyond their perhaps irritating profit-making use of our collections we see some service areas we need to consider-evaluation and repackaging of information. I believe if you did a survey and evaluation, and repackaging was suggested as a possible new service, you'd have a lot of interested people. Maybe we don't want to go the full nine yards on this, but what's the vision and how might 
this work in? Those of us who provide service to area businesses evaluate and repack information as a matter of course. There is an analogy here that might be useful. The larger department stores have developed a new service-a wardrobe consultant. There is usually a single individual in a nicely furnished office who, by appointment, will devote her entire attention to you, the customer, as you spend your money in putting together a few pieces for a fall wardrobe, or whatever. The counterpart in the library is the individual who has an in-depth reference need and in meeting that need will also spend money on database searches, interlibrary loan fees, or document delivery services. If we look at pricing these needed services with a profit in mind, we may be able to throw in the consultant free.

The last area I will mention really tears down the walls and crosses sacred boundaries. I have felt for a long time that librarians should be playing a significant role in the organization and dissemination of campuswide information. We have a host of campus units, from contracts and grants to registrar, holding information critical to the academic process in forms and formats incompatible between systems and unavailable to decision makers. Librarians, with their long history of cooperatively establishing standards and facilitating access, have the exact set of skills needed to address these problems. This paradigm shift, should we be successful in pulling it off, raises all the issues I mentioned earlier-it's not your job, it's not my image of your abilities, etc. It's interesting territory that is rife with more political problems than with information access problems. The February issue of Academic Computing 5 has more of my view on this issue, if you'd like to pursue it further. I believe there is a critical opportunity here.

\section{The environment of change}

Where does all of this leave us? I've tried to challenge your thinking with regard to old patterns and habits and suggested some service areas we need to pay particular attention to as we move deeper into the electronic jungle, as it's been called. I'd like to emphasize, again, the role of a vision and downplay hard-core plans. Visionary leadership in the face of budget cuts can truly turn disasters into assets-it's not easy but it can be done. We need supervisors who spend more of their time looking toward the future and looking for opportunities to move the unit toward the vision while spending less time focusing on today and the

${ }^{5}$ Pat Molholt, "Libraries and Campus Information: Redrawing the Boundaries," Academic Computing 4 (February 1990): 20-21, 42-43. close supervision of employees-although a little ankle biting is ok. Equally important, the employees need to understand where the organization is going-that, in fact, it is not sitting still, but is moving deliberately toward a vision, and what they do matters a great deal in the progress toward that goal. Not everyone will agree with the directionand yes, moving a behemoth is not easy-but a vision that translates down to every individual can make it move.

The organization within which this will be happening in the '90s will be different too. First, the hierarchies, the chain of command, will be flatter, with increased responsibility and accountability pushed down to those individuals capable of effecting change. There will be more negotiation and facilitation in a lateral fashion rather than movement up, over, and down. This will be a deregulated, decentralized world where responsiveness to individual customer and patron needs is feasible and rewarded.

Second, successful organizations will need to be faster in responding to change and absorbing new ideas. The process of planning will be more important than the plan, which will be in constant flux. The ability to put together teams, to effect tradeoffs, to experiment, to take risks will be important. These are not characteristics bred into us in our graduate programs.

Finally, there is the element of change itself, the force prodding the behemoth on. We need to learn to live with change and anticipate it, not always reacting after having run into it. Widen your sights; look outside the profession for indicators of change in the broader community. Ask "what if?" questions $\ldots$ and dream.

\section{Local CE Courses in high demand}

Requests for ACRL's Local Continuing Education Presentations are coming in from coast to coast and even from the islands.

In addition to the seven classes being presented in Puerto Rico at the University of Puerto Rico, Ponce, Local CE Presentations are being made in Oklahoma, Georgia, Washington D.C., Minnesota, California, Ohio, and Pennsylvania.

Local Presentations are professional development opportunities that are brought directly to your campus. With the increase in requests comes an increasing need for skilled instructors. If you are interested in joining our Professional Development Training Team please call Mattye Nelson, (312) 280-2519 or Reggie Prim (312) 280-2526. 